\title{
Khaled A. Alnefaie* \\ Strength and modulus of carbon nanotubes under a tensile load
}

\begin{abstract}
Carbon nanotubes (CNTs) were fabricated using low-pressure chemical vapor deposition and then embedded in epoxy polymer at several weight ratios, 0, 0.75, 1.5, and $3 \mathrm{wt} \%$, for tensile testing and Young's modulus determination using an Instron machine. The tensile strength and Young's modulus of the epoxy resin were increased with the addition of CNTs to a certain extent, and then decreased with the increase in the weight fraction of CNTs. The best properties occurred at $1.5 \mathrm{wt} \%$ of CNTs. Scanning electron microscopy was used to reveal the dispersion status of CNTs in the nanocomposites.
\end{abstract}

Keywords: carbon nanotubes; epoxy polymer; mechanical properties; polymer nanocomposites.

DOI 10.1515/jmbm-2014-0002

\section{Introduction}

A polymer is a long molecule consisting of many small units (monomers) connected end to end. Polymers have low stiffness and strength compared with metals. These properties can be improved by adding reinforcements such as fibers, tubes, or particles. The reinforced polymeric material is known as a composite material with non-isotropic physical properties but is orthotropic. A nanocomposite material is defined as a multiphase solid material with one of the phases consisting of at least one dimension of $<100 \mathrm{~nm}$, or constructions having nanoscale recurrence intervals between the different phases that form the material [1].

Materials comprising nanometer-size particles have been found to produce exceptional mechanical properties compared with their micron-size equivalents. At room temperature, Mayo et al. [2] obtained strain-rate sensitivity measurements that indicate the ductile behavior of nanophase ceramics. Guermazi et al. [3] reported substantial deformation of dense nanophase $\mathrm{TiO}_{2}$ without fracture

*Corresponding author: Khaled A. Alnefaie, Faculty of Engineering, Mechanical Engineering Department, King Abdulaziz University, P.O. Box 80204, Jeddah 21589, Saudi Arabia,

e-mail: kalnefaie@kau.edu.sa or cracking at elevated temperature. Similarly, Jain and Christman [4] reported similar results in their experiments on a crusted nanophase intermetallic composite. Chen et al. [5] compared the nano and micro sizes of $\mathrm{TiO}_{2}$ filler in an epoxy resin. They found that the nanocomposite exhibited a remarkable increase in the modulus and the strain to failure as compared with pure epoxy and microcomposite.

The production of nanotubes in large quantities can be done using different techniques. These include chemical vapor deposition (CVD), arc discharge, laser ablation, and high-pressure carbon monoxide. CVD is the most promising for industrial-scale deposition. It took until 1993 [6] for nanotubes to actually be produced by using this technique, although the CVD of carbon was initially stated by Walker et al. [7] in 1959. Recently, an $18 \mathrm{~cm}$ array length of aligned carbon nanotubes (CNTs) was reached by Wang et al. [8].

Research studies in the literature presented strong evidence that CNTs have remarkable mechanical properties. Owing to their exceptional thermomechanical, chemical, and optoelectronic properties, CNTs are becoming increasingly promising materials for modern technology applications (nanocomposites, nanodevices, nanoelectronics, nanomedicine). In spite of this, the explicit determination of the mechanical properties of these nanotubes is a challenging assignment because of the technical obstacles engaged in handling them. Experimental measurements and theoretical estimates on these materials have shown that the elastic modulus of these nanotubes is between 0.5 and $1 \mathrm{TPa}$, and tensile strength in the range of 50-200 GPa, which makes them perfect candidates for composites reinforcement [9-13]. The superior strength and unusual deformability of CNTs have been the subjects of a number of recent studies, specifically the dispersing of CNTs in low-strength polymers to improve their mechanical properties [14-19]. Although the reported measurements of modulus values for CNTs were high, polymer nanocomposites have not exhibited the anticipated scales of stiffness improvement because of few crucial matters mainly associated to morphology and processing [20-22]. For example, Cebeci et al. [23] investigated the elastic modulus of a composite formed from aligned multiwalled CNTs having 0.5 TPa modulus embedded in an aerospace 
grade structural epoxy resin. The measured composite modulus was $8.8 \mathrm{GPa}$, while the expected value was 100 $\mathrm{GPa}$. Moreover, they found that the elastic modulus of the composite increased with increasing the volume fraction of the embedded multiwalled nanotubes.

This research article presents the fabrication of CNTs by using low-pressure CVD (LPCVD) to be embedded in epoxy polymer at several weight ratios for tensile testing and Young's modulus determination.

\section{Experimental and methods}

\subsection{Materials}

The LPCVD method was used in this study to grow the CNTs. The average diameter and length of the tubes were found to be 20 and $1000 \mathrm{~nm}$, respectively. The hardener (curing agent) was cobalt naphthenate (Alfa AesarJohnson Matthey Management GmbH \& Co Karlsruhe, Germany), approximately 53\% in mineral spirits (6\% Co) and MEKP. Other materials used were ethanol as solvent to dilute the epoxy resin, mold release agent (Ease Release 200, Mann Release Technologies Inc., Easton, PA, USA), and Fosroc Solvent 102 (Fosroc Limited, Staffordshire, $\mathrm{UK})$.

\subsection{Preparation method}

A substrate of silicon wafer was coated with iron nanoparticles as a catalyst, using an LPCVD machine manufactured by Syskey Technology Ltd., Jhubei City, Taiwan (Figure 1). Ferrocene (Wuxi Weite New Engery Co., Ltd., Jiangsu, China) was used as a catalyst, while acetylene $\left(\mathrm{C}_{2} \mathrm{H}_{2}\right)$ was used as a carbon precursor along with nitrogen $\left(\mathrm{N}_{2}\right)$ as a process gas. CNTs at $0,0.75,1.5$, and $3 \mathrm{wt} \%$ of epoxy resin samples were prepared. First, CNTs were dispersed in ethanol and mixed mechanically for $10 \mathrm{~min}$ at $2000 \mathrm{rpm}$. Then, epoxy resin was added to this solution. Next, to obtain a homogeneous dispersion, the mixture was sonicated by using an ultrasonicator machine, Branson 2510, for $12 \mathrm{~h}$. For the removal of the ethanol, the mixture was then placed in a low-power ultrasonic bath (Branson 2510, Branson Ultrasonics Corp., Danbury, CT, USA) for another $12 \mathrm{~h}$. The residual ethanol was removed by evaporation in vacuum. Thereafter, the hardener was added to the combination and mechanically mixed for $20 \mathrm{~min}$. Finally, the mixture was molded and cured at room temperature.
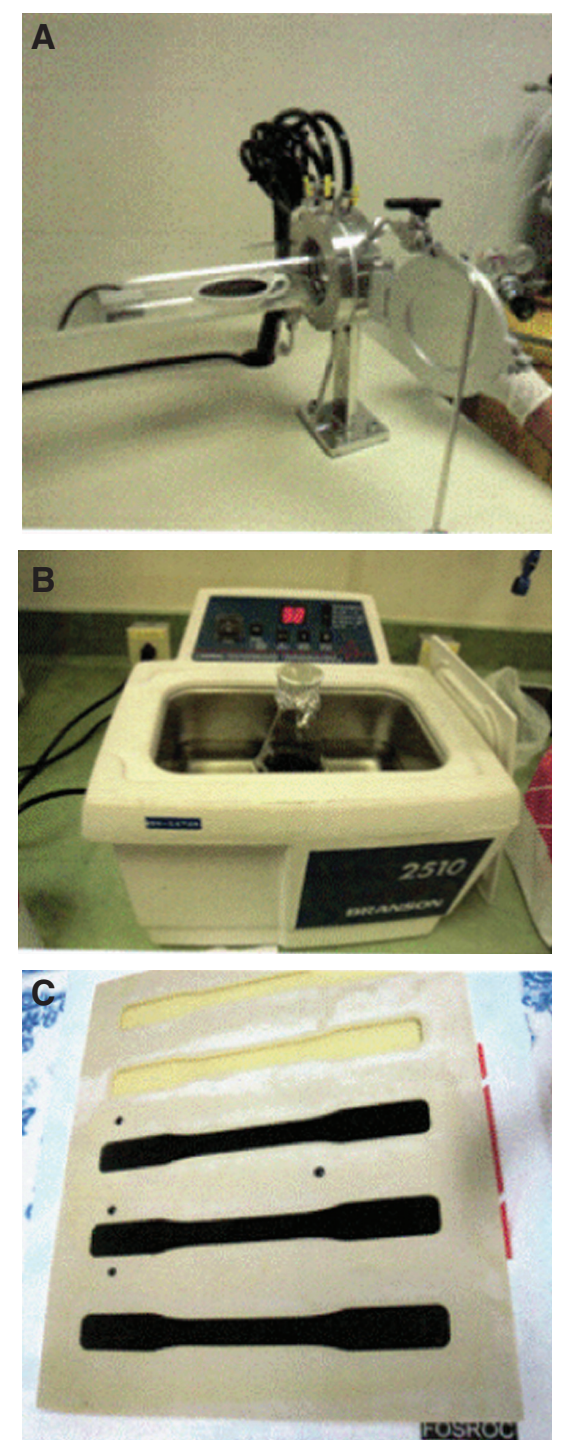

Figure 1 (A) LPCVD machine used in this study. (B) Ultrasonication of the mixture. (C) Molded samples.

\subsection{Characterization methods}

\subsubsection{Micro Raman spectroscopy}

A micro Raman spectrometer was used to determine if the tested samples were taking more of a graphite shape than an amorphous shape, or vice versa. The Raman spectrum was measured using a DXR Raman microscope from Thermo Scientific (Saudi Arabia), with a 532-nm laser as excitation source at a power of $8 \mathrm{~mW}$. The spectrum was measured in the $50-3600 \mathrm{~cm}^{-1}$ zone. The spectral resolution was $3 \mathrm{~cm}^{-1}$. The result indicated that the structure of the CNTs was taking more of a graphite shape. 


\subsubsection{Scanning electron microscopy}

The morphologies of the resulting CNTs were analyzed by scanning electron microscopy (SEM). SEM images were captured for the fabricated nanotubes. The microscopic morphology was examined by using the FEI Magellan 400L system (FEI Company, Hillsboro, USA). Transmission electron microscopy (TEM) images of CNTs at high resolution were also obtained.

\subsubsection{Mechanical analysis}

To evaluate the effects of adding CNTs on the tensile strength of the composite samples, tensile tests were conducted on the cured samples according to ASTM D638 using the universal testing machine Instron 3369 (Instron Corporation, Norwood, MA, USA), at a load of $50 \mathrm{kN}$ and a rate of $5 \mathrm{~mm} / \mathrm{min}$.

\section{Results and discussion}

\subsection{SEM and TEM results}

A set of techniques can be used to achieve characterization of carbon nanostructures. Electron microscopy techniques (SEM and TEM) are among the most frequently used methods. Figure 2 depicts an SEM image of CNTs at low and high magnifications at $3 \mathrm{wt} \%$ of CNTs. The figure shows the yielded nanotubes shuffled in a noodle-like manner with a considerable yield of Y-junction CNTs. As seen in the figure, there is a significant aggregation of CNTs in the CNT/epoxy nanocomposites at $3 \mathrm{wt} \%$ of nanotubes. This would affect the strength of nanocomposites as these aggregates form stress concentration regions. The inner core of these CNTs was repeatedly constantly filled with the catalyst material and had a role in facilitating the filling of tubes.

Figure 3 shows a high-resolution TEM (HR TEM) image of CNTs. The HR TEM technique is effectively essential in assessing the characteristics of CNTs as this method can observe samples at greater magnifications. As shown in Figure 3, the CNTs were distributed uniformly in size. This distribution was affected by the diameter distribution of the particles used. The figure also shows the formation of buds and multiple Y-junction CNTs.

\subsection{Mechanical properties}

The impact of nanoparticle dispersion in epoxy resin on the mechanical properties of nanocomposites was
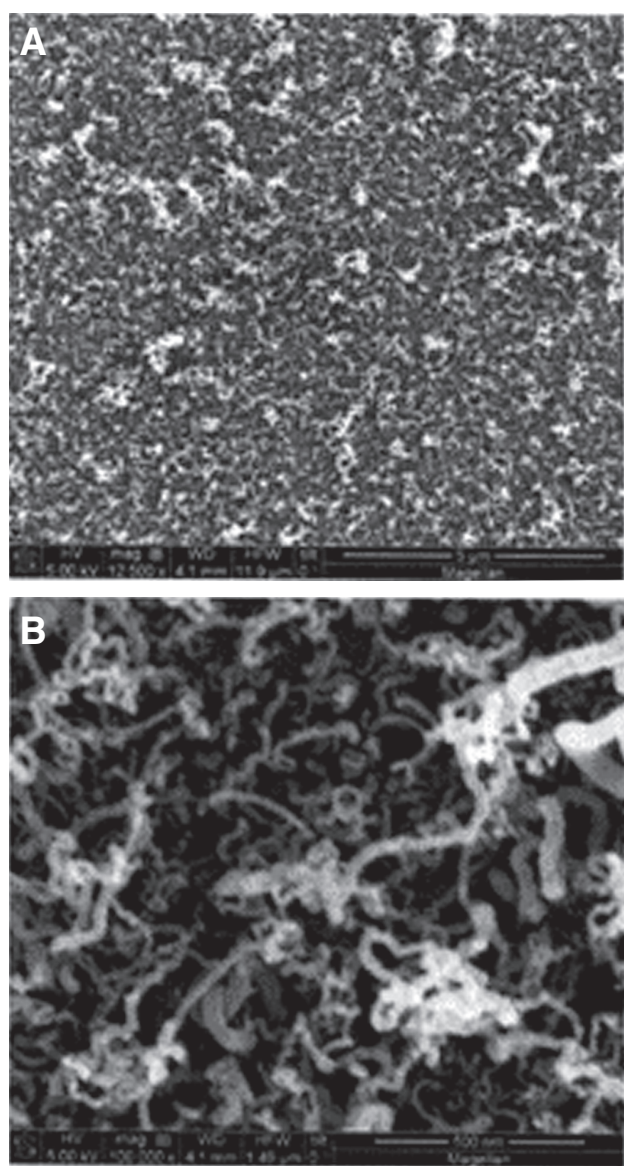

Figure 2 (A) Example of SEM image of the CNTs at low magnification. (B) Example of SEM image of the CNTs at high magnification (case $3 \mathrm{wt} \%$ ).

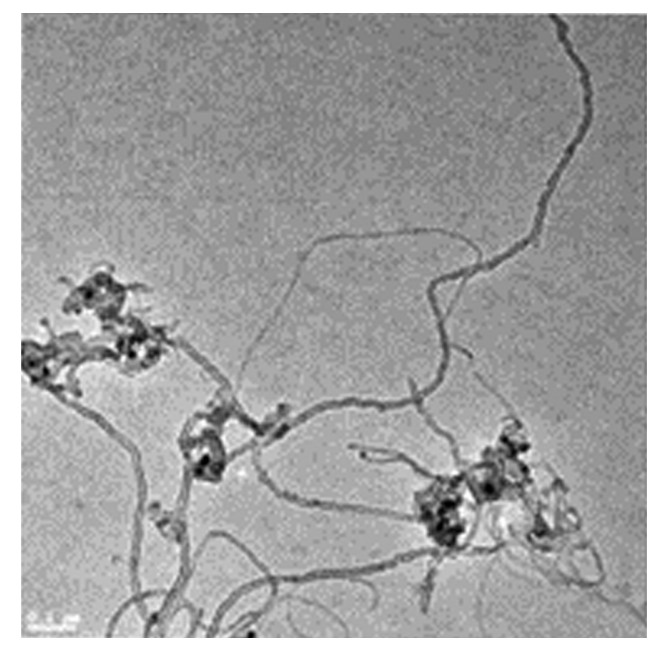

Figure 3 HR TEM image of the CNTs at $0.1 \mu \mathrm{m}$.

the main objective of this research study. Figure 4 shows the tensile strength results of CNT/epoxy composites. On the basis of the results achieved, about 


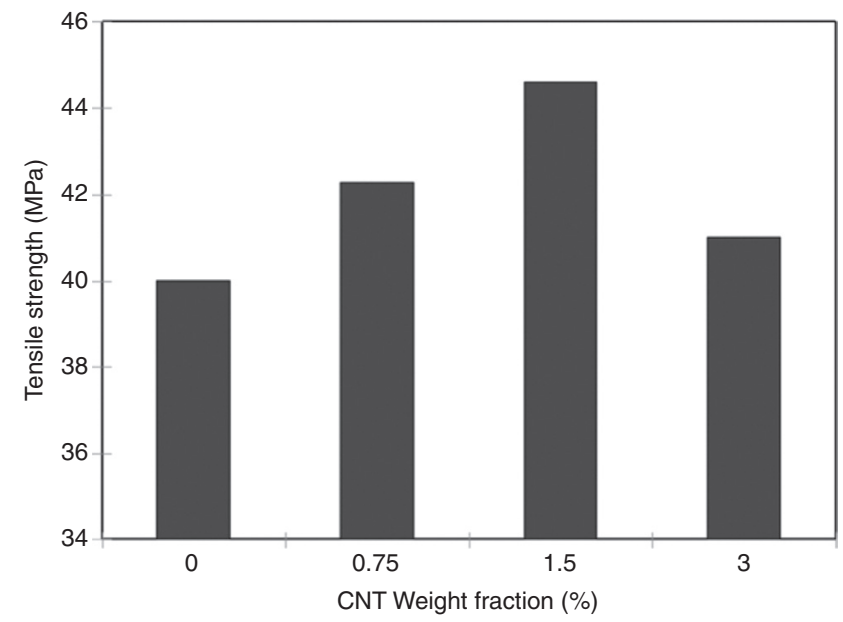

Figure 4 Tensile strength of CNT/epoxy nanocomposites in various CNT weight fractions.

$5.8 \%$ enhancement on tensile strength was obtained by adding $0.75 \mathrm{wt} \%$ of CNT to epoxy resin. Moreover, increasing the amount of CNT content increased the tensile strength, which reached a peak improvement of $11.5 \%$ at $1.5 \mathrm{wt} \%$ of CNT content and then decreased at $3 \mathrm{wt} \%$ of CNT content. Figure 5 shows the Young's modulus of the resulting nanocomposites. Similar to the results of tensile strength, the optimum amount of Young's modulus was attained at $1.5 \mathrm{wt} \%$ of CNT content. At $3 \mathrm{wt} \%$ of CNT, both tensile strength and Young's modulus were decreased. Random orientation and aggregation of the CNTs inside the nanocomposites at higher weight fraction of CNTs might be the reason for such a conduct. Another possible reason

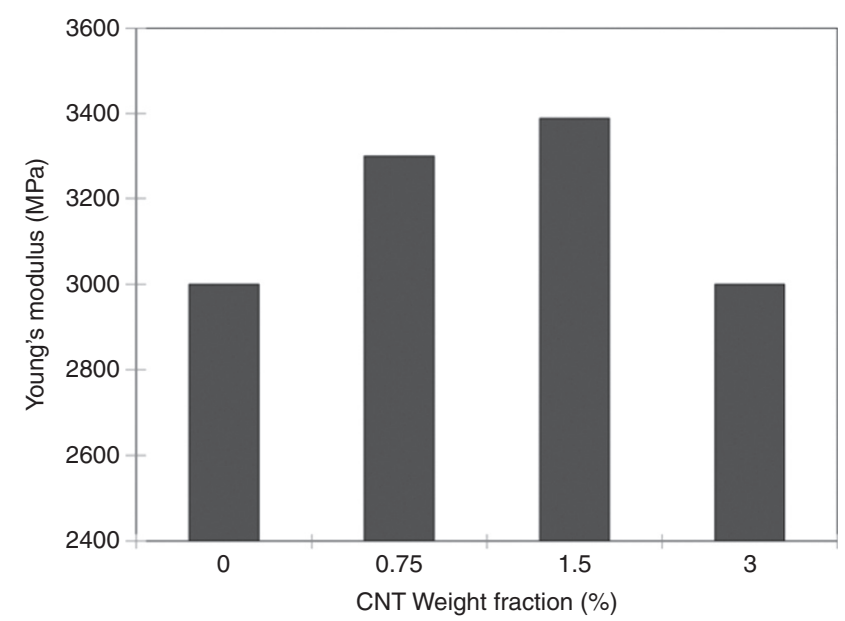

Figure 5 Young's modulus of CNT/epoxy nanocomposites in various CNT weight fractions. that might be responsible for such an act is the dispersion status of the CNTs. Attaining a homogenous dispersion is a challenging task because of their intense trend to aggregate.

\section{Conclusions}

One of the main goals of this research article was to test the effect of reinforcing epoxy polymer with CNTs. The tensile strength and Young's modulus of CNT/epoxy nanocomposites at different weight ratios of nanotubes $(0,0.75$, 1.5 , and $3 \mathrm{wt} \%$ ) were examined. The results revealed that tensile strength and Young's modulus of the epoxy resin were increased with the addition of CNTs to a certain extent, and then decreased with the increase in the weight fraction of CNTs. This might have happened owing to the random orientation and aggregation of the CNTs inside the nanocomposites at a higher weight fraction of CNTs. This led to the formation of stress concentration regions and reduced the strength of nanocomposites. The best tensile strength and Young's modulus occurred at $1.5 \mathrm{wt} \%$ of CNTs.

\section{References}

[1] Ajayan PM, Schadler LS, Braun PV. Nanocomposite Science and Technology. Wiley-VCH Verlag GmbH \& Co. KGaA, Germany, 2004.

[2] Mayo MJR, Siegel W, Naryanasamy A, Nix WD. J. Mater. Res. 1990, 5, 1073-1082.

[3] Guermazi M, Hofler HJ, Hahn H, Averback RS. J. Am. Ceram. Soc. 1991, 74, 2672-2680.

[4] Jain M, Christman T. Acta Metall. Mater. 1994, 42, 1901-1911.

[5] Chen Q, Schadler LS, Siegel RW, Irvin GC, Mendel J. Materials Research Society Symposium Proceedings - Symposium T - Polymer Nanocomposites. Nutt S, Vaia R, Rodgers W, Hagnauer GL, Beall GW, Eds., Curran Associates Inc., CA, USA, 2002.

[6] Jose-Yacaman M, Miki-Yoshida M, Rendon L, Santiesteban JG. Appl. Phys. Lett. 1993, 62, 657-659.

[7] Walker PL, Rakszawski JF, Imperial GR. J. Phys. Chem. 1959, 63, 133-140.

[8] Wang X, Li Q, Xie J, Jin Z, Wang J, Li Y, Jiang K, Fan S. Nano Lett. 1999, 9, 3137-3141.

[9] Treacy MMT, Ebbesen TW, Gibson JM. Nature 1996, 381, 678-680.

[10] Wong EW, Sheehan PE, Lieber CM. Science 1997, 277, 1971-1975.

[11] Yu MF, Lourie O, Dyer MJ. Science 2000, 287, 637-640.

[12] Poncharal P, Wang ZL, Ugarte D, Heer WA. Science 1999, 283, 1513-1516.

[13] Salvetat JP, Bonard JM, Thomson NH, Kulik AJ, Forro L, Benoit W, Zuppiroli L. Appl. Phys. A 1999, 69, 255-260. 
[14] Coleman JN, Khan U, Blau WJ, Gun'ko YK. Carbon 2006, 44, 1624-1652.

[15] Moniruzzaman M, Winey KI. Macromolecules 2006, 39 , 5194-5205.

[16] Park SH, Bandaru P. Polymer 2010, 51, 5071-5077.

[17] Martone A, Formicola C, Giordano M. Compos. Sci. Technol. 2010, 70, 1154-1160.

[18] Shokrieh MM, Saeedi A, Chitsazzadeh M. J. Nanostruct. Chem. 2013, 3, 1-5.
[19] Yang JP, Chen ZK, Feng QP, Deng YH, Liu Y, Ni QQ. Compos. Part B-Eng. 2013, 43, 22-26.

[20] Thostenson ET, Chou TW. J. Phys. D Appl. Phys. 2002, 35, 77-80.

[21] Thostenson ET, Chou TW. J. Phys. D Appl. Phys. 2003, 36, 573-583.

[22] Lau K, Wong T, Leng J, Hui D, Rhee KY. Compos. Part B-Eng. 2013, 54, 41-43.

[23] Cebeci H, Villoria RG, Hart AJ, Wardle BL. Compos. Sci. Technol. 2009, 69, 2649-2656. 